\title{
Introducing and Testing a Measurement Tool for English Language Proficiency: Aisha's Tool
}

\author{
Aisha M. Alhussain ${ }^{1}$ \\ ${ }^{1}$ Princess Nourah University, Riyadh, Saudi Arabia \\ Correspondence: Aisha M. Alhussain, Princess Nourah University, Riyadh, Saudi Arabia. E-mail: \\ amalhusian@pnu.edu.sa
}

Received: March 2, 2019 Accepted: March 28, 2019 Online Published: May 8, 2019

doi:10.5539/ijel.v9n3p319 URL: https://doi.org/10.5539/ijel.v9n3p319

\begin{abstract}
The IELTS English proficiency tests are discussed as being highly effective in determining students' level of proficiency in the language. However, the study points out that the processes involved in the administration of the tests along with the associated cost make affect the effectiveness of its use in the assessment of learners. A Sentence Pattern test is offered as an alternative with 97 participants taking part in the assessment to test its effectiveness. Each of the non-native study participants is subjected to both the SP test and the IELTS test for the establishment of the correlation in the results posted for the two tests. The findings demonstrate that the students' performance in the IELTS test correlated with their corresponding SP test results. High performing students in the IELTS test also posted high scores in their SP test. As demonstrated in the study, the correlation in the results illustrates the effectiveness of the SP test as an alternative for the IELTS tests in proving English language proficiency.
\end{abstract}

Keywords: proficiency test, sentence patterns, measurement tool, IELTS

\section{Introduction}

English is widely used as the language of instruction, which makes it necessary to ensure that applicants that get admitted to foreign universities within English speaking countries express proficiency in it. In the United States, students' proficiency in the English language has been assessed through Test of English as a Foreign Language (TOEFL) tests while other institutions use the International English Language Testing System (IELTS). The latter currently remains the most popular means of examining proficiency in the language. The scores in the latter are then used in assessing one's level of proficiency based on The Common European Framework of Reference for Languages (CEFR). While the use of IELTS has been effective in facilitating assessment of English proficiency for determination of admissions for non-native speakers, the study, therefore, aims at proposing an English Proficiency measurement tool that will help ensure that learners are subjected to equally effective testing measures, but that is faster and free. Through the study conducted, a correlation is established between the test scores from the proposed tool and the ones featured by the learners through their IELTS result and CEFR levels. The fact that the assessment was conducted in comparison to scores featured by non-natives, as will be demonstrated, further helped make clear the effectiveness of the proposed tool.

\section{Literature Review}

The failure to assess enough skills when testing proficiency remains a significant problem given the cost of the tests. Time has also been regarded as a key factor of consideration for both the individuals administering the tests and the ones taking them. Consequently, the users of test scores end up using non-comprehensive assessment of the critical abilities or skills necessary to establish language proficiency. According to (Powers, 2010), the assessment of English language has been the most limited. One of the questions that the author evaluates in the study is whether a single measure, often the ability to read or speak, can suffice as a determinant of proficiency for a given test taker for all communication modes in the English language. It is notable that the various communication modes in the language include reading, speaking, listening, reading, and writing (Iwashita, Brown, McNamara, \& O'Hagan, 2008). While the ability to speak may appear to be the most significant of the noted skills, the performance that the test taker demonstrated also have a strong influence over the way in which they interact through the language in other areas. For instance, learning through the language requires the application of all the remaining skills, which is a suggestion of the fact that focus on speaking alone during the 
tests may be insufficient. Powers (2010) argues that a student's performance in all the four skills is often rated very highly, which implies that it would be unreasonable to assess proficiency based on a single measure.

The identification of whether a given English proficiency test is appropriate, according to Norris (2012), is often a daunting task. The fact that alternatives include a variety of approaches is cited as the primary factor that influences the difficulty in deciding the test that would be appropriate. Therefore, the difficulty of administering the test, given Norris perspective, may play a central role in shaping the outcome of the assessment. Norris also states that language tests are procedures or instruments through which the assessor gathers specific kinds of information that has to do with the learners' abilities in language. One important element to take into account is that the conducting of the tests also includes consideration for the need to ensure high retention rates of the international students admitted (Nassaji \& Fotos, 2004). With the focus on the fact that the language of instruction influences learning the nature of tests administered become a critical factor of consideration (Wait \& Gressel, 2009).

Lahib (2016) also argues that it is important to conduct a comprehensive ability evaluation to ensure that students can interact effectively through the language. Lahib states that learners who are not Native English speakers have to provide proficiency test results as evidence of their ability to communicate effectively in English. The requirement, given the need to ascertain both English speaking ability and academic capability, tests that have broadly, but effectively, evaluated the applicant's potential to communicate in English to ensure success in their academic throughout their learning in the institution to which they are admitted (Nassaji \& Fotos, 2004). The argument, therefore, leads to consideration for approaches that have been used over the past and the limitations that have been associated with them (Morrow, 2018). While the tests remain highly comprehensive, ensuring that they are fully administered remains the biggest problem (Lee, 2004). The cost factor remains a significant influence over the comprehensiveness of the process for most students who seek to take the test for admission (Powers, 2010).

The identified constraint often leads to the restriction of the process to tests focusing on listening and speaking ability (Kaliyadan, Thalamkandathil, Parupalli, Amin, Balaha, \& Ali, 2015). While both skills are important determinants of the learners' abilities in the language, they still fall short of the actual measures necessary for the certain verification that the language can be used for issuing an instruction to the learners throughout their education in the institution to which they are admitted. While Powers (2010) does not assert the weakness of most of the contemporary assessment measures, he points out that the constraints that affect them may render the ultimate test results inadequate. In arguing for the need to focus on the nature of assessment conducted rather than student tests, Norris (2012) contends that every test measure assesses skills that are highly significant.

According to Wait and Gressel (2009), there is a sharp correlation between the performance demonstrated by students in history, philosophy, business, and Humanity disciplines and their English-speaking abilities. In their findings, Wait and Gressel demonstrate that while other disciplines such as Engineering are not significantly affected by the level of the learners' proficiency, the use of language still makes it important in determining the ease of their academic experience. The arguments presented by Wait and Gressel feature as evidence of the fact that the nature and purpose of any given test have a strong influence on the success realized in identifying whether a student can communicate effectively in English. Contemporary tests, as argued, successfully demonstrate the skills that the learner has (Lee, 2004). However, it is imperative to consider the ease of administering them given the need to ensure that the learners take them all for clear feedback (Bernhardt, 2000).

Aside from the time and cost factor that may affect the test process, Norris (2012) asserts that it is important to focus on the intended use of the test as a determinant of its appropriateness in determining a learners' language abilities. Therefore, he proposes four components that need to be taken into account when evaluating the intent of the test to determine its effectiveness. The primary element he focuses on is the "what" factor (Stein et al., 2012). The element focuses on the information offered through the test. The second aspect he introduces is "who", which focuses on the test user. Other elements include the "impact" which is about the test consequences, and the "why" aspect, which is an analysis of the purpose for the administration of the test (Nassaji \& Fotos, 2004). The four elements are meant to help one establish whether the test chosen will successfully evaluate all skills necessary to determine the learners' ability to communicate fully using the language (Nassaji \& Fotos, 2004).

It is possible to predict a person's abilities in speaking English through the use of their listening and speaking skills. The two skills stand out as the most focused on during the administering of the tests (Luk \& Bialystok, 2013). However, it is important to consider that a sole focus on the two elements is insufficient to help offer an elaborate picture of the individual's abilities, as discussed. While most institutions focus on competitive 
processes, the cost factor and the time-consuming nature of most tests make it difficult to follow up and ensure that the learners complete the entire evaluation process (Yen \& Kuzma, 2009). The impact that the cost factor has had on the effectiveness of the evaluation process, therefore, necessitates testing measures that will see to comprehensive assessments without limitations such as time and cost factors (Galaczi, 2018).

It is notable that there are eight basic parts of speech that make up the sentence patterns in English (García \& Cain, 2014). Each of the four assessable skills is dependent on a person's understanding of sentence patterns. The tool focuses on the assessment of the use of these sentence patterns, with the view of establishing the student's grammar abilities. The demonstration of the ability to understand grammar implies capability to formulate sentences well both in writing and in speech (Granger, 2009). It also means that the student can comprehend and use language in its correct context. The focus on identification of different sentence structures, therefore, ensures that the learner is examined for all the four skills without having to diversify the test processes, which features as the main advantage of the tool besides the fact that it is free for use (Hsu, 2010).

\section{Study Significance}

Language proficiency tests, as noted through the literature review, bear great significance given the increase in enrolments into foreign universities. The fact that English remains the most common language of instruction has further necessitated the need to ensure that the students that gain enrolment demonstrate an adequate level of proficiency. According to Wait and Gressel (2009), language proficiency plays a determinant role in the academic performance of learners in disciplines such as humanities and business. Despite the apparent essence of ensuring that learners are adequately proficient in English, the difficulty and cost of the process of administering common tests have made it difficult for the process to take place comprehensively. The cost factor, for instance, has resulted in the reduction of the proficiency elements that are often tested (Little, 1998). Rather than focus on tests that cover both the oral and written skills, processes have been limited to oral skills. The issue has led to the view that speech proficiency effectively demonstrates adequate abilities in the language.

Contrary to the view, language proficiency requires that all the four proficiency elements are tested. These elements include speaking, listening, reading, and writing. The study seeks to evaluate the effectiveness of a cheap alternative that ensures that students can be subjected to comprehensive tests that can help offer a clear judgment of their level of proficiency as the conventional testing measures. Knowledge of sentence patterns entails an understanding of the way in which sentences are formulated (Kobayashi, 2002). Sentence patterns are instrumental in giving meaning to words. For ESL learners, the knowledge of sentence patterns is essential for the understanding of the meaning of the various language aspects as they appear in a sentence. Similarly, the understanding of sentence structure ensures that one can be able to express their thoughts effectively in both writing and speech. The fact sentence structure differs across different languages further demonstrates the essence of ensuring that ESL learners have adequate knowledge of sentence structures. Sentence structures, therefore, help to ensure that sentences have meaning and that they feature thoughts coherently. While a person may be able to listen to and understand English language, their ability to speak and write remains dependent on their knowledge of sentence structures. Therefore, their skills in the language is considered a critical element in ensuring that they can take tests in the language and succeed in them. The fact that there are numerous types of sentences that make up grammar in English as a language means that it is important that learners demonstrate the ability to identify the various parts that make up the whole structure.

When seeking to write a sentence in English, one must use the important parts that include the subjects and verbs. The way in which one puts the verbs, subjects, and other elements of a sentence together results in the expression of their thoughts in a means that can be understood (Sundari, 2013). A sentence such as 'Smith walked' features the use of a noun and a verb. In this case, 'Smith' is the subject and 'walked' is the verb. The sentence may be modified to 'Smith is walking.' In this case focus may be on the agreement of the verb with the subject which is Smith. It is imperative that subject-verb agreement features in the sentence for it to have meaning (Shiotsu \& Weir, 2007). This implies that if a speaker does not understand the concept of subject-verb agreement, they are unlikely to be able to express themselves coherently in speech and writing. With focus on the study participants' understanding of sentence structures, the research demonstrates the essence of the tool in making a quick determination of whether one can express themselves effectively in speech and writing, an element that also proves their reading and listening skills.

\section{Methodology}

The study was conducted based on assessment results collected from 97 participants from Swansea University in the UK (Native English Speakers) and Princess Nourah bint Abdulrahman University, Riyadh, Saudi Arabia. The test processes required that the students take two different versions of the test that included the identification 
of the sentence patterns. The students were required to respond to two versions of the tests, each requiring a simple yes/no answer on the suggested pattern of the sentence. The essence of having the students take two tests was to ensure that their results could be verified. Each of the tests provided results that were averaged to evaluate their level of proficiency. It is notable that the test does not focus on a comparison of the level of proficiency of the non-native speakers against the native speakers. The average scores collected from the test process were then averaged and recorded. The study also required that a record of the students' test result on IELTS tests be recorded for comparison. The IELTS tests focused on the assessment of the four areas of skills (speaking, listening, reading, and writing) for a clear understanding of the applicability of the tool under review for proficiency testing. It is also notable that the IELTS test scores were only recorded for the non-native speakers. The result was then analyzed using SPSS to help in the establishing of the correlation between the test scores collected following the use of the proposed tools and the scores recorded from the IELTS tool. The design of the test was as follows;

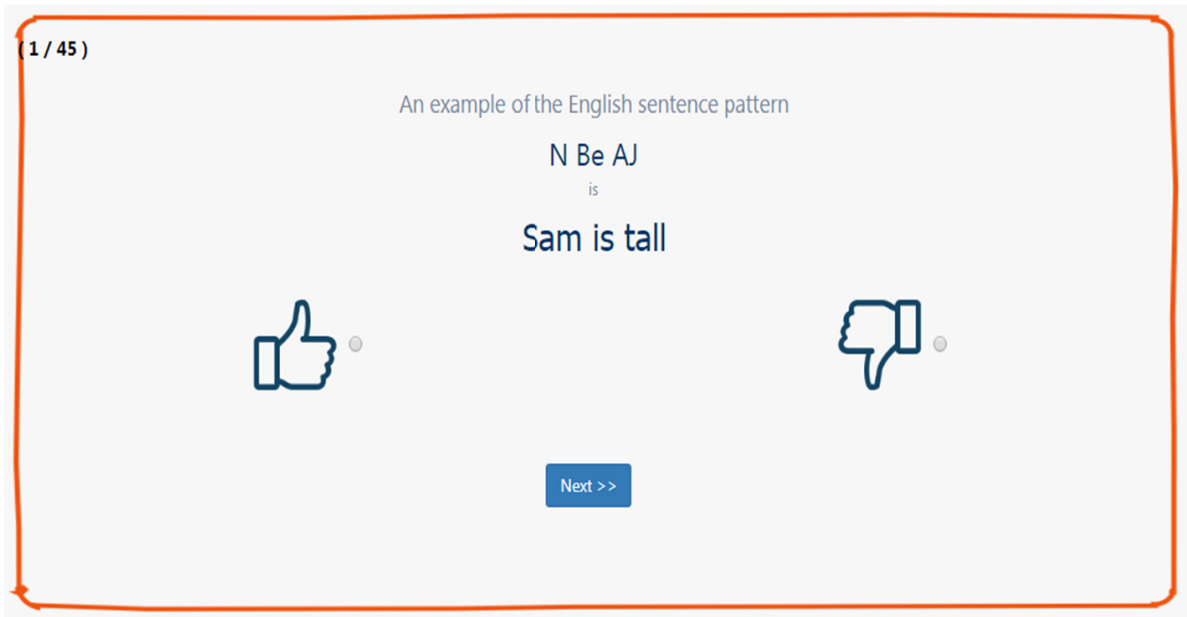

Figure 1. Sample of the test format

Explanation for the symbols used in the test:

$\mathrm{N}=$ Noun; $\mathrm{Be}=$ Verb to be; $\mathrm{AJ}=$ Adjective; $\mathrm{AV}=$ Adverb; LV = Linking Verb; InV = Intransitive Verb; $\operatorname{TrV}=$ Transitive Verb;

N1 \& N1 = both nouns have the same referent;

$\mathrm{N} 1 \& \mathrm{~N} 2=$ Nouns have 2-different referents;

N1 \& N2 \& N3 =Nouns have 3 different referents;

$\mathrm{N} 2 \& \mathrm{~N} 2=$ The second and the third nouns have the same referents.

The tool (http://aishatool.com) features sentences with different patterns. The participants in the test were required to analyze sentences and identify the patterns that were presented. Patterns included the sentences with nouns, the verb be in its conjugated form, and an adjective, adverb, intransitive verb, transitive verb, or linking verb. Other structural elements that are assessed through the tool include whether nouns have common referents. The process included agreeing to the proposed pattern for a sentence that features. From Figure 1, an example of an English patterns sentence is featured. Here, the respondent is expected to either agree or disagree with the proposed pattern according to their analysis of the pattern featured in the sentence. A similar question is featured for part B of the test, which was meant to help in verifying the first results and eliminating the errors that featured.

\section{Results}

The test results featured mixed scores for both the natives and the non-natives. Through the results posted by the students, it was possible to establish a correlation that can be used in illustrating the applicability of the tool in conducting proficiency test. Figure 1 features the correlation of the results posted by a section of the non-native study participants. It is worth noting that a total of 97 students took the test through the proposed tool. The 
results were sampled variously to establish the correlation between the test findings registered following use of the tool and the results from the IELTS test conducted.

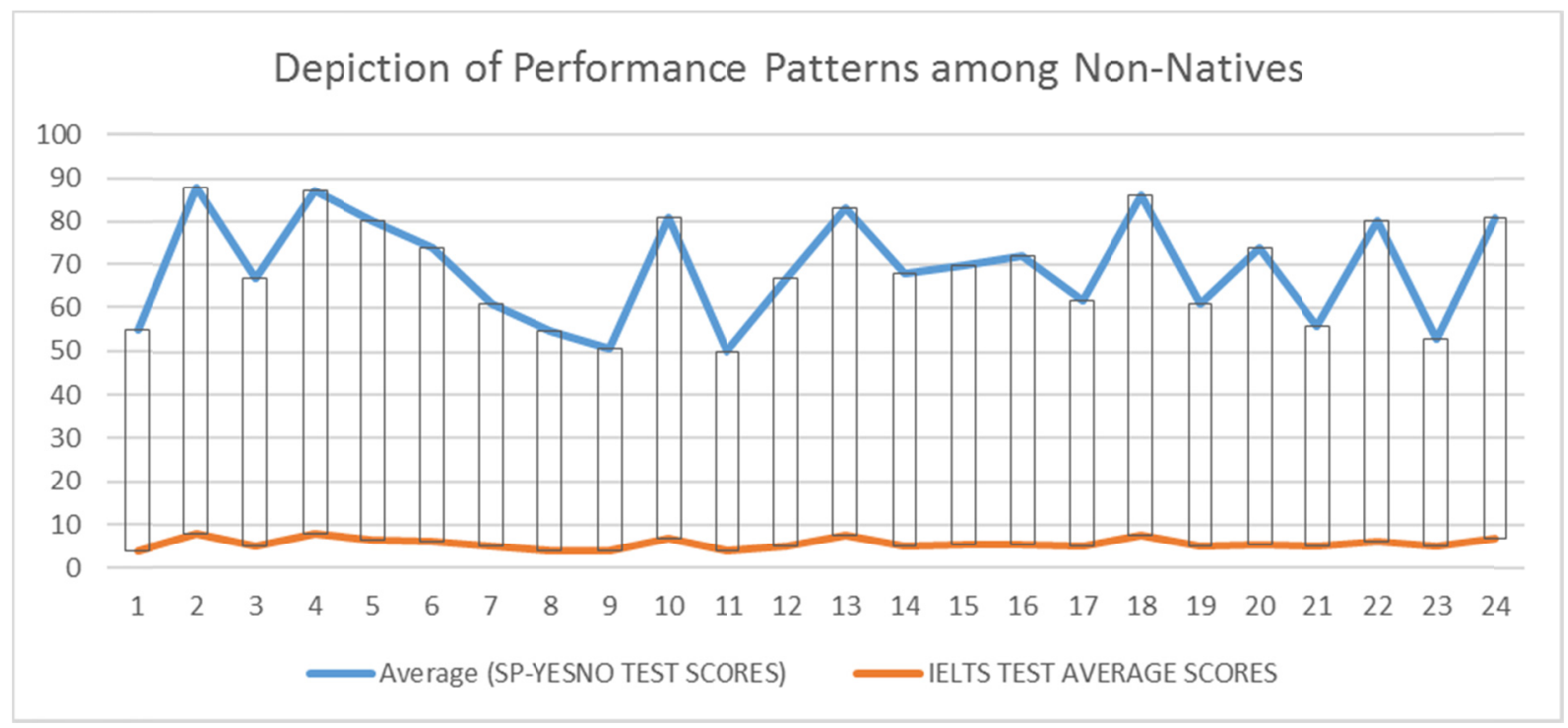

Figure 2. Comparison of results from a randomly selected section of the non-native study participants

It is notable that the IELTS proficiency test scores are computed out of 10. The students that post results closer to 10 have a high level of proficiency. Lower the scores mean that the student has a low level of proficiency. Similarly, proficiency from the proposed test is assessed concerning how high the students' average scores are. Figure 2 features the sampling of results from 24 students that were randomly selected from the list of non-natives that took the test. The focus on non-natives through this section of the analysis was influenced by the fact that they have results from both the use of the proposed tool and the IELTS test results. The goal of this section of the analysis was to demonstrate the correlation that their results feature. From the figure, it is apparent that high points in the average SP scores correlate with the high scores in the IELTS test average test scores. The results suggest that the students who fall with the range of $\mathrm{B} 2$ to $\mathrm{C} 1$ (above average to good proficiency levels) also posted high average results through their responses in the in the SP-YESNO test.

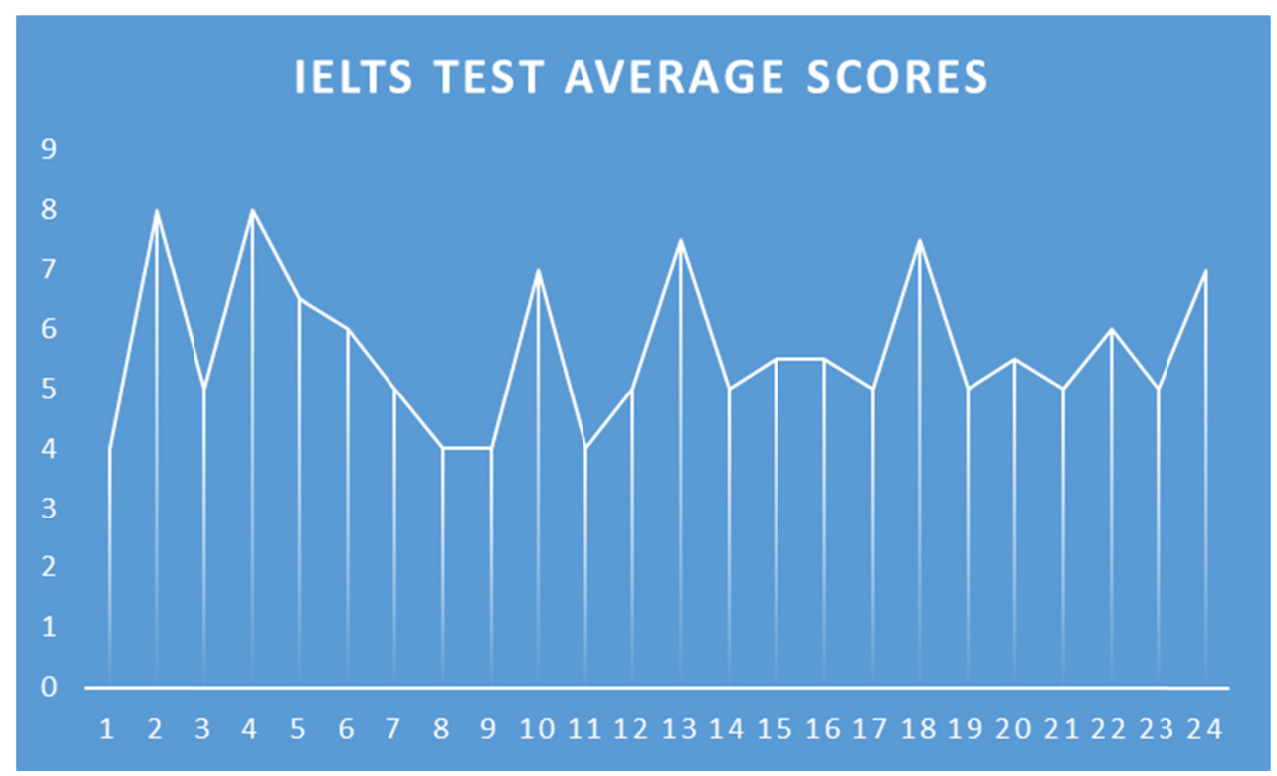

Figure 3. IELTS test average scores for randomly selected non-native study participants 


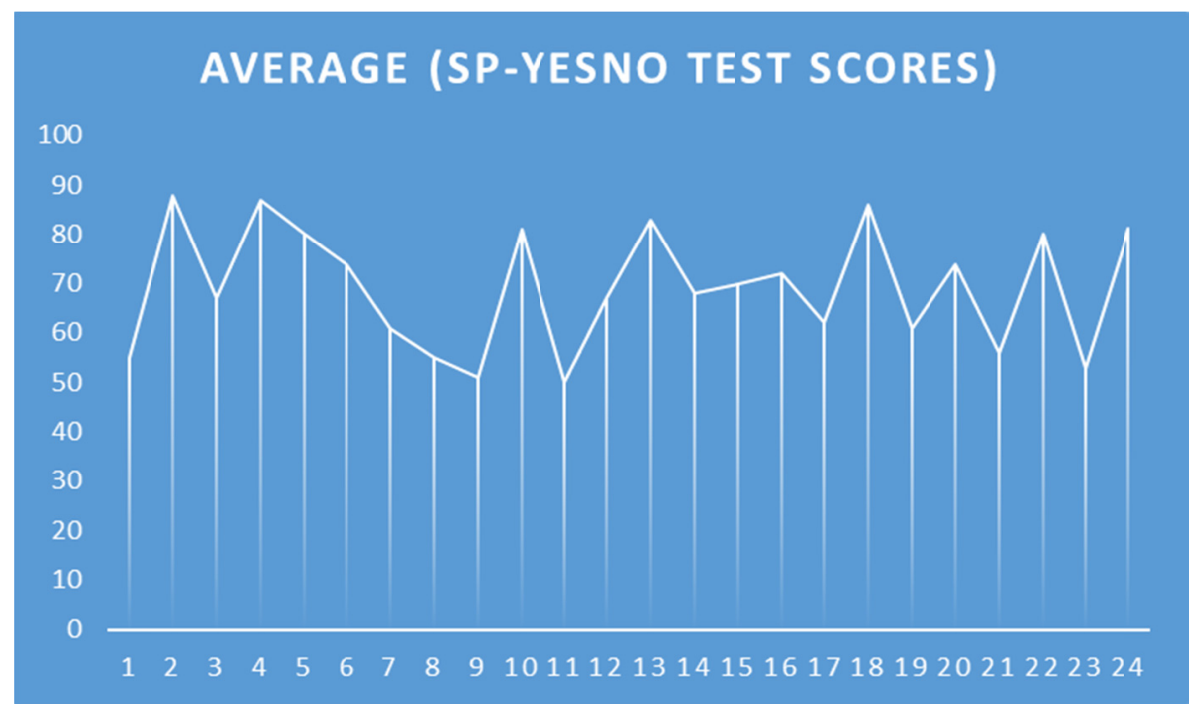

Figure 4. Average SP-YESNO test scores for randomly selected non-native study participants

From the results posted, there is also a clear closeness between the results posted by the students in both test types. For instance, student 8 and 9 in Figure 3 were established to have posted the same results in the IELTS test. With average scores of 4 each, the students' proficiency level was classified at B1 according to the CEFR level measure. A focus on the scores of the same students as featured in Figure 4 makes apparent the correlation between their results. While student 8 posted an average score of 55 in the SP-YESNO test, student 9 registered an average of 51. In both tests, the closeness of their scores is apparent. A focus on student 2, 3 and 18 (also randomly selected) also helps to illustrate the correlation in the results that were posted in both tests. In the IELTS test scores, the students registered 8,5 and 7.5 respectively. According to the CEFR level rating, student 2 and 18 are categorized in the $\mathrm{C} 1$ level while student three is classified in the B1. The results posting featured through Figure 4 justify the scores recorded, as the students posted equally high results to demonstrate the level of their proficiency. Student 2 posted an average of 88 while student 18 posted an average of 86 . Student 3 posted an average of 67 , which is consistent with the intermediate resulted posted in the IELTS test taken.



Figure 5. Comparison of results from the non-native speakers 
Another measure that significant for the study is the test scores posted by the native English speakers. From the computing of the scores, their average score was noted to be 65 , which implies that most fall within the bracket of B2 proficiency according to the CEFR levels rating. While the study was not focused on a comparison between the native speakers and non-native speakers, some elements were made apparent from the computing of the average. It is notable that the IELTS tests assess different elements, including the speaking, writing, listening, and reading skills.

While the native speakers did not take part in the IELTS tests, their level of proficiency was still assessed through the SP-YESNO test. The apparent variance in the results that were posted by the students accounts for the variance in skills other than listening and speaking.



Figure 6. Average SP-YESNO test scores for native speakers

From the presented chart, it is evident that unlike the non-native speakers, none of the native speakers posted average results that fell below $50 \%$, which suggests that while their abilities in the four skill areas may vary, their proficiency in listening and speaking contributed to the results that they posted. Their results also help in the justification of the findings that were posted by the non-native speakers, some of whom scored below $50 \%$. The fact that the non-native speakers that posted results below $50 \%$ also featured below average test scores in the IELTS test accounts helps feature the correlation of the test results as featured in the presented graphs.

\section{Discussion}

According to Batstone and Ellis (2009), the evaluation of one's abilities in any given language is based on the level of their comprehension of the language. The study further points out that the ability to identify the various elements that make up any given sentence is critical in enabling one's understanding of a language irrespective of the skill being assessed. For instance, for a person to learn how to read, it is important that they be able to demonstrate adequate knowledge of elements of a sentence structure such as the subject-verb agreement. Similarly, a person's listening and comprehension skills is based on their ability to understand the ways in which different parts of a sentence relates (Akbari, 2014). Through the understanding of sentence patterns one is able to distinguish between ideas that captures the aspect of the past and ones that focus on the present. Through the argument presented Akbari (2014) states that syntax in a given sentence is a core element in the prediction of one success when reading. Syntax also effectively contributes to the ease of identifying between a student who is good at reading and one who is poor in the skill (Akbari, 2014). A proper understanding of the essence of the measures of oral language that include syntax and vocabulary, therefore, makes it easier to identify a student who may be stated to be well proficient in the language.

Gascoigne (2005) acknowledges that reading, writing, listening and speaking are all critical elements to consider when assessing someone's level of proficiency in the English language. Gascoigne (2005) also supports the assertions through findings demonstrating that grammar is a critical component in ensuring the effectiveness of 
one's comprehension of English as a second language. Through focusing on various aspects of grammatical knowledge, the study demonstrates that the knowledge of sentence patterns is a critical determinant of one's ability to show the various skills that make necessary for effective communication in the English language - speaking, reading, writing and listening. The study helps demonstrate that a person's level of language proficiency can only be effectively guaranteed if their grammar skills are effective (Gascoigne, 2005).

In the results presented from the study undertaken, it is evident that there is an apparent correlation between the results posted in the IELTS test and the corresponding results in the Sentence Pattern test. The relationship implies that it is unlikely for one to post high results in the sentence pattern test if they fail to register high scores in the IELTS tests taken (Hungyo \& Kijai, 2009). This finding from the presented study is corroborated by the arguments presented given the fact that the Sentence Pattern test focuses on the assessment of one's grammatical abilities. As Nassaji (2002) argues, grammatical knowledge is an effective predictor of one's level of English language comprehension and can also successfully indicate their reading capability. The author also argues that the core part of a person's grammatical abilities includes their understanding of the relationship between sentences, an element that is entirely reliant on the understanding of sentence patterns.

As apparent, the non-native participants in the study had to take IELTS test which includes the assessment of all the four skills that help determine a student's level of proficiency (Alderson, 2005). However, with the presented arguments, it is evident that all the four skills are fully dependent on a person's knowledge of sentence patterns, a fact that is proven by the evident correlation between the SP results posted by each student and their corresponding IELTS results. The apparent correlation in the study participants' performance in the two tests indicates that the tests can be effectively used as substitutes for each other. It is notable that the focus of the IELTS tests is majorly on establishing one's level of proficiency based on the abilities demonstrated through the four skills assessed (Brimo, Apel, \& Fountain, 2017). The Sentence Pattern test, on the other hand, assesses one's grammatical abilities through an evaluation of their knowledge of sentence structures. This implies that a person would not be able to succeed in correctly identifying sentence structures if their level of English proficiency is low (Burt, Peyton, \& Adams, 2003). Similarly, a person is not able to complete the sentence patterns test successfully is unlikely to be successful in completing the four-skill assessment carried out through IELTS tests.

Brimo, Apel and Fountain (2017) state that the IELTS tests are highly effective in enabling the successful evaluation of one's English proficiency. Part of the elements that make the IELTS tests effective includes the fact that they not only focus on a single skill but address the various elements that determine one's competency (Hungyo \& Kijai, 2009). Part of the factors that have reduced the effectiveness of the use of the IELTS tests includes the fact that it is costly and time consuming to carry out a full assessment of all the presented skills (Brimo, Apel, \& Fountain, 2017). Over the past, it has been established that some students undertake incomplete tests, which make it difficult to establish their actual level of proficiency in the language. It is factual that IELTS tests are highly effective as apparent (Brimo, Apel, \& Fountain, 2017). However, the cost factor and the time associated with the administration of the tests make it less convenient compared to the sentence pattern test.

It is notable that the administration of IELTS tests often requires one-on-one interaction with the examiner, which features as a significant advantage (Han \& D'Angelo, 2009). However, it is notable that the need to ensure that the examiner is directly involved is also one of the critical limitations that may be associated with the process (Alderson, 2005). As stated, the process requires time and is costly as the examiner has to subject the test-taker through different sessions with each involving the two directly. The test process means that an exam taker has to take at least 2 hours 45 minutes to complete the test (Batstone \& Ellis, 2009). It is factual that the IELTS tests remain highly effective. However, the associated constraints demonstrate the Sentence Pattern test can be an effective alternative. The fact that the test results demonstrate a direct correlation between the two steps shows that the SP test can be successfully used as a substitute for the IELTS test.

An analysis of the sentence pattern test demonstrates that it does not require the direct supervision of the examiner. The fact that the tool collects data directly as the participant continues to take the test means that the scores are available at the end of the test. This implies that the test can be administered in a much shorter time than required for the IELTS test. Another critical consideration is that the Sentence Pattern test is free and can be readily accessible, which makes it an ideal substitute. The fact that the test focuses on one's ability to identify sentence structures means that it is focused on the student's grammatical abilities, which cover all the assessable aspects in evaluating the level of English proficiency (Butler, 2004).

As apparent from the presented findings the non-native study participants took IELTS tests before taking the Sentence Pattern test. The areas that were focused on their IELTS tests include their listening, speaking, reading, 
and writing skills (Burt, Peyton, \& Adams, 2003). The featured areas are central to the effectiveness of the IELTS tests undertaken to verify one's level of proficiency in the language. While the study participants were 97 , only the non-native speakers were subjected to IELTS testing. However, both the native speakers and the non-native speakers participated in the Sentence Pattern tests. The focus on the high number of participants was highly important in ensuring that the findings were credible and that the results could be used in determining the effectiveness of the SP test (Butler, 2004).

Table 1. Test results for 80 participants from the study

\begin{tabular}{|c|c|c|c|c|c|c|c|c|c|c|c|}
\hline $\begin{array}{l}\text { Participant } \\
\text { (User } \\
\text { Account } \\
\text { Number) }\end{array}$ & $\begin{array}{l}\text { SP-test } \\
\text { scores }\end{array}$ & $\begin{array}{l}\text { IELTS } \\
\text { test } \\
\text { Scores }\end{array}$ & Participant & $\begin{array}{l}\text { SP-test } \\
\text { scores }\end{array}$ & $\begin{array}{l}\text { IELTS } \\
\text { test } \\
\text { Scores }\end{array}$ & Participant & $\begin{array}{l}\text { SP-test } \\
\text { scores }\end{array}$ & $\begin{array}{l}\text { IELTS } \\
\text { test } \\
\text { Scores }\end{array}$ & Participant & $\begin{array}{l}\text { SP-test } \\
\text { scores }\end{array}$ & $\begin{array}{l}\text { IELTS } \\
\text { test } \\
\text { Scores }\end{array}$ \\
\hline 24 & 78 & 6.5 & 40 & 69 & 5 & 76 & 81 & 6.5 & 115 & 55 & 4 \\
\hline 25 & 75 & 6.5 & 42 & 50 & 4 & 77 & 78 & 6.5 & 117 & 53 & 4 \\
\hline 27 & 71 & 5.5 & 46 & 88 & 8 & 80 & 80 & 6.5 & 118 & 59 & 4.5 \\
\hline 29 & 79 & 6.5 & 56 & 71 & 5.5 & 82 & 74 & 6 & 119 & 51 & 4 \\
\hline 31 & 55 & 4 & 57 & 90 & 8 & 84 & 84 & 7.5 & 125 & 59 & 4.5 \\
\hline 32 & 85 & 8 & 63 & 67 & 5 & 90 & 61 & 5 & 138 & 81 & 7 \\
\hline 36 & 69 & 5 & 65 & 51 & 4 & 107 & 50 & 4 & 141 & 72 & 5.5 \\
\hline 71 & 87 & 8 & 74 & 86 & 8 & 109 & 71 & 5.5 & 26 & 54 & 4 \\
\hline 72 & 91 & 8.5 & 75 & 73 & 6 & 112 & 52 & 4 & 47 & 62 & 5 \\
\hline 59 & 50 & 4 & 184 & 83 & 7.5 & 121 & 60 & 5 & 187 & 81 & 7 \\
\hline 64 & 51 & 4 & 172 & 71 & 5.5 & 142 & 63 & 5 & 166 & 71 & 6 \\
\hline 83 & 66 & 5 & 178 & 68 & 5 & 196 & 90 & 8 & 174 & 88 & 7.5 \\
\hline 95 & 52 & 4 & 183 & 76 & 6.5 & 181 & 66 & 5 & 150 & 56 & 5 \\
\hline 189 & 75 & 6 & 179 & 70 & 5.5 & 143 & 74 & 6 & 190 & 80 & 6 \\
\hline 168 & 86 & 7.5 & 173 & 64 & 5 & 182 & 73 & 6 & 165 & 64 & 5.5 \\
\hline 147 & 55 & 5 & 180 & 75 & 6 & 186 & 67 & 5 & 191 & 55 & 5.5 \\
\hline 148 & 61 & 5 & 146 & 72 & 5.5 & 197 & 71 & 5.5 & 151 & 53 & 5 \\
\hline 167 & 75 & 6 & 192 & 83 & 7 & 194 & 73 & 6 & 175 & 80 & 6 \\
\hline 171 & 77 & 6.5 & 169 & 62 & 5 & 193 & 80 & 6.5 & 156 & 49 & 4.5 \\
\hline 149 & 74 & 5.5 & 170 & 73 & 6 & 145 & 82 & 7 & 152 & 87 & 6.5 \\
\hline
\end{tabular}

One important factor to take into consideration from the presented findings is the fact that the results are analyzed in segments to help achieve clarity in the correlation made apparent from the line graphs plotted. For instance, Figure 2 features the results of 24 participants selected randomly from the list if the non-native study participants. The results feature both their scores from the Sentence Pattern Test and the IELTS Test that were taken. From the sample of the picked segment, it is evident that the study participants that registered high scores for their SP test also registered high scores in the IELTS test taken. For instance, participant number one from the results sampled in Figure 2 is noted to have scored slightly below average results in the IELTS test, which correlated with the score of 55 in the SP pattern test taken.

Similarly, the participant number 2 from the figure, as apparent, registered a score of 8 in the IELTS test undertaken. His high scores coincided with the score of 85 registered in the SP test undertaken. Similar trends are demonstrated in the results analyzed in the other sections.

In the results, it is apparent that the Native speakers' average score was noted to be 65 , which implies that most fall within the bracket of B2 proficiency according to the CEFR levels rating. While the study was not focused on a comparison between the native speakers and non-native speakers, some elements were made apparent from the computing of the average. It is notable that the IELTS tests assess different elements, including the speaking, writing, listening, and reading skills. While the native speakers did not take part in the IELTS tests, their level of proficiency was still assessed through the SP-YESNO test. The apparent variance in the results that were posted by the students accounts for the variance in skills other than listening and speaking. This aspect of the findings is further evidence of the relationship between one's knowledge of sentence patterns and their ability to utilize the other skill sets that contribute to their level of proficiency (Akbari, 2014). Nonetheless, the result they posted help demonstrate that basic understanding of the English language is directly dependent on a person's grammar abilities, which are also shaped by their knowledge of sentence patterns (Akbari, 2014). 


\section{Conclusion}

The goal of the study was to examine the effectiveness of the sentence pattern tool for use in conducting proficiency assessment test among student as an alternative to IELTS tests. The findings demonstrate that there is a direct correlation between the test scores posted in IELTS and the ones posted in the SP test. A student with high IELTS test scores also registers high scores in the SP test while a student with lower scores in IELTS posts low results in the corresponding IELTS results. It is also apparent from the results discussed following the study that the SP test helps the student experience the assessment of elements that shape their abilities in all the fours skill-set necessary for the establishment of whether one is proficient in the English Language. The study demonstrates a consensus among many researchers on the fact that IELTS tests are effective in establishing one's level of English proficiency. However, they also assert the limitation associated with the IELTS test processes. For instance, the IELTS test processes are noted to be time-consuming and costly. This is featured as one of the factors that have influenced the taking of incomplete tests that ultimately make it difficult to justify one's level of proficiency. The Sentence Pattern test features is a cheaper alternative given that it does not require an independent assessment of individual skills - reading, writing, listening, and speaking - that shape a student's overall ability in the language. The Sentence Pattern test also makes it possible to ensure that all elements of the assessment processes are covered, which makes it highly effective.

\section{References}

Akbari, Z. (2014). The role of grammar in second language reading comprehension: Iranian ESP context. Procedia-Social and Behavioral Sciences, 98, 122-126. https://doi.org/10.1016/j.sbspro.2014.03.397

Alderson, J. C. (2005). Assessing reading. Ernst Klett Sprachen.

Batstone, R., \& Ellis, R. (2009). Principled grammar teaching. System, 37(2), 194-204. https://doi.org/10.1016/j.system.2008.09.006

Bernhardt, E. B. (2000). Second-language reading as a case study of reading scholarship in the 20th century.

Brimo, D., Apel, K., \& Fountain, T. (2017). Examining the contributions of syntactic awareness and syntactic knowledge to reading comprehension. Journal of Research in Reading, 40(1), 57-74. https://doi.org/10.1111/1467-9817.12050

Burt, M., Peyton, J. K., \& Adams, R. (2003). Reading and Adult English Language Learners: A Review of the Research. National Center for ESL Literacy Education (NCLE). ED505537

Butler, Y. G. (2004). What level of English proficiency do elementary school teachers need to attain to teach EFL? Case studies from Korea, Taiwan, and Japan. Tesol Quarterly, 38(2), 245-278. https://doi.org/10.2307/3588380

Galaczi, E. (2018). Benefits of testing the four skills (reading, listening, writing and speaking). Retrieved from https://www.cambridgeenglish.org/blog/benefits-of-testing-the-four-skills/

García, J. R., \& Cain, K. (2014). Decoding and reading comprehension: A meta-analysis to identify which reader and assessment characteristics influence the strength of the relationship in English. Review of Educational Research, 84(1), 74-111. https://doi.org/10.3102/0034654313499616

Gascoigne, C. (2005). Toward an understanding of the relationship between L2 reading comprehension and grammatical competence. The Reading Matrix, 5(2).

Granger, S. (2009). More lexis or grammar? What does the learner corpus say? Keynote presentation at the. In Third International Conference Grammar and Corpora. 22-24 September. Retrieved from https://uclouvain.be/en/research-institutes/ilc/cecl/must.html

Han, Z. H., \& d'Angelo, A. (2009). Balancing between comprehension and acquisition: Proposing a dual approach. Second Language Reading Research and Instruction: Crossing the Boundaries, 173-191.

Hsu, H. F. (2010). The impact of implementing English proficiency tests as a graduation requirement at Taiwanese universities of technology. Doctoral dissertation, University of York. Retrieved from https://core.ac.uk/download/pdf/40039368.pdf

Hungyo, J., \& Kijai, J. (2009). The Effect of Integrated and Segregated Skills Approach on English Language Acquisition among Freshmen Nursing and Business Students in Mission College, Thailand. Scriptor, 10, 21. Retrieved https://docplayer.net/29478587-Integration-of-the-four-skills-of-the-english-language-and-its-influence-on-t he-performance-of-second-grade-high-school-students.html\#tab_1_1_2 
Iwashita, N., Brown, A., McNamara, T., \& O'Hagan, S. (2008). Assessed levels of second language speaking proficiency: How distinct? Applied Linguistics, 29(1), 24-49. https://doi.org/10.1093/applin/amm017.

Kaliyadan, F., Thalamkandathil, N., Parupalli, S. R., Amin, T. T., Balaha, M. H., \& Ali, W. H. A. B. (2015). English language proficiency and academic performance: A study of a medical preparatory year program in Saudi Arabia. Avicenna Journal of Medicine, 5(4), 140. https://doi.org/10.4103/2231-0770.165126

Kobayashi, M. (2002). Method effects on reading comprehension test performance: Text organization and response format. Language Testing, 19(2), 193-220. https://doi.org/10.1191/02655322021t227oa

Lahib, S. (2016). Testing Tensions: The Use of English Language Proficiency Tests for the Admission of Ontario High School Applicants to One Ontario University. Retrieved from https://ir.lib.uwo.ca/etd/4000/

Lee, S. (2004). Teaching lexis to EFL students: A review of current perspectives and methods. Annual Review of Education, Communication and Language Sciences, 1(22), 12-27.

Little R, J., A. (1998). A test of missing completely at random for multivariate data with missing values. Journal of the American Statistical Association, 83, 1198-1202. https://doi.org/10.1080/01621459.1988.10478722

Luk, G., \& Bialystok, E. (2013). Bilingualism is not a categorical variable: Interaction between language proficiency and usage. Journal of Cognitive Psychology, 25(5), 605-621. https://doi.org/10.1080/20445911.2013.795574

Morrow, C. K. (2018). Communicative language testing. The TESOL Encyclopedia of English Language Teaching, 1-7. https://doi.org/10.1002/9781118784235.eelt0383

Nassaji, H. (2002). Schema theory and knowledge - based processes in second language reading comprehension: A need for alternative perspectives. Language Learning, 52(2), 439-481. https://doi.org/10.1111/0023-8333.00189

Nassaji, H., \& Fotos, S. (2004). 6. Current developments in research on the teaching of grammar. Annual Review of Applied Linguistics, 24, 126-145. https://doi.org/10.1017/S0267190504000066

Norris, J. M. (2012). Purposeful Language Assessment: Selecting the Right Alternative Test. English Teaching Forum, 50(3), 41-45.

Powers, D. E. (2010). The case for a comprehensive, four-skill assessment of English-language proficiency. $R \&$ D Connections, 14, 1-12.

Shiotsu, T., \& Weir, C. J. (2007). The relative significance of syntactic knowledge and vocabulary breadth in the prediction of reading comprehension test performance. Language Testing, 24(1), 99-128. https://doi.org/10.1177/0265532207071513

Stein, M., Federspiel, A., Koenig, T., Wirth, M., Strik, W., Wiest, R., \& Dierks, T. (2012). Structural plasticity in the language system related to increased second language proficiency. Cortex, 48(4), 458-465. https://doi.org/10.1016/j.cortex.2010.10.007

Sundari, H. (2013). Mastery of Simple Sentence Patterns in Writing Class. English Education, 1(3).

Wait, I. W., \& Gressel, J. W. (2009). Relationship between TOEFL score and academic success for international engineering students. Journal of Engineering Education, 98(4), 389-398. https://doi.org/10.1002/j.2168-9830.2009.tb01035.x

Yen, D., \& Kuzma, J. (2009). Higher IELTS score, higher academic performance? The validity of IELTS in predicting the academic performance of Chinese students. Worcester Journal of Learning and Teaching, 3. Retrieved from https://eprints.worc.ac.uk/811/

\section{Copyrights}

Copyright for this article is retained by the author, with first publication rights granted to the journal.

This is an open-access article distributed under the terms and conditions of the Creative Commons Attribution license (http://creativecommons.org/licenses/by/4.0/). 